\title{
Rational selection of antifungal drugs to propose a new formulation strategy to control Candida biofilm formation on venous catheters
}

\section{Paula Reginatto ${ }^{1,2}$ (D) Vanessa Zafanelli Bergamo ${ }^{1}$ - Simone Jacobus Berlitz ${ }^{3}$ Irene Clemes Kulkamp Guerreiro ${ }^{3,4,5}$. Saulo Fernandes de Andrade ${ }^{1,4,5}$. Alexandre Meneghello Fuentefria ${ }^{1,4,6}$}

Received: 13 December 2019 / Accepted: 6 February 2020 / Published online: 19 February 2020

(C) Sociedade Brasileira de Microbiologia 2020

\begin{abstract}
Introduction Infections associated with medical devices are often related to colonization by Candida spp. biofilm; in this way, numerous strategies have been developed and studied, mainly in order to prevent this type of fungal growth.

Aim Considering the above, the main objective of the present study is to make a rational choice of the best antifungal therapy for the in vitro treatment of the biofilm on venous catheters, proposing an innovative formulation of a film-forming system to coat the surface in order to prevent the formation of biofilms.

Methodology Anidulafungin, fluconazole, voriconazole, ketoconazole, amphotericin B, and the association of anidulafungin and amphotericin B were tested against biofilms of C. albicans, C. tropicalis, and C. parapsilosis strains in microtiter plates and in a polyurethane catheter. Besides, anidulafungin, amphotericin B, and the combination of both were incorporated in a filmforming system and were evaluated against biofilm.

Results The superior activity of anidulafungin was demonstrated in relation to the other antifungal agents. Although amphotericin B showed good activity, high concentrations were required. The combination showed a synergistic action, in solution and in the formulation, showing excellent results, with activity above $90 \%$.

Conclusion Due to the superiority of anidulafungin and the synergistic activity of the combination, these alternatives were the most promising options for use in a formulation proposal as a new strategy to combat the Candida spp. biofilm. These formulations demonstrated high in vitro performance in the prevention of biofilms, indicating that they are candidates with great potential for in vivo tests.
\end{abstract}

Keywords Catheter $\cdot$ Polyurethane $\cdot$ Association $\cdot$ Film-forming system $\cdot$ Biofilm

Responsible Editor: Rosana Puccia

Electronic supplementary material The online version of this article (https://doi.org/10.1007/s42770-020-00242-z) contains supplementary material, which is available to authorized users.

Paula Reginatto

paula.reginatto@ufrgs.br

1 Programa de Pós-Graduação em Microbiologia Agrícola e do Ambiente, Universidade Federal do Rio Grande do Sul, Porto Alegre, Brazil

2 Laboratório de Micologia Aplicada, Faculdade de Farmácia, Universidade Federal do Rio Grande do Sul, Porto Alegre, RS, Brazil
3 Programa de Pós-Graduação em Nanotecnologia Farmacêutica, Universidade Federal do Rio Grande do Sul, Porto Alegre, Brazil

4 Programa de Pós-Graduação em Ciências Farmacêuticas, Universidade Federal do Rio Grande do Sul, Porto Alegre, Brazil

5 Departamento de Produção de Matéria-Prima, Faculdade de Farmácia, Universidade Federal do Rio Grande do Sul, Porto Alegre, Brazil

6 Departamento de Análises, Faculdade de Farmácia, Universidade Federal do Rio Grande do Sul, Porto Alegre, Brazil 


\section{Introduction}

Systemic infections caused by Candida spp. are associated with a high rate of morbidity and mortality, longer hospital stay, and high health care costs $[1,2]$. Although $C$. albicans is the most frequent species, Candida non-albicans has been showing an increase in its frequency, overall, C. parapsilosis and $C$. tropicalis $[2,3]$. Candida spp. is the third major cause of catheter-related infections and this has been shown to support colonization and biofilm formation, notably C. albicans and C. parapsilosis. Biofilm is a highly structured, coordinated, and functional community of cells adhering to the surface and associated with each other (with properties different from the respective planktonic cells); this cell community is surrounded by a self-produced protective extracellular matrix $[4,5]$. Thus, this biofilms are associated with increasing the outcome of patients' fatality [6-9].

In cases of suspected catheter blood infection with Candida species, the recommendation is always to remove it, followed by the introduction of the antifungal therapy $[10,11]$. In cases of patients whose removal of the catheter represents risks greater than the benefits, treatment for the permanence of the device becomes necessary $[7,8,10]$. Thus, some of the most effective methods for the management of clinically important fungal biofilms are to inhibit the development of the biofilm or to disturb it mechanically [12]. The strategies developed in recent years for its management include (i) the impregnation of the material with antimicrobial substances, such as the antimicrobial lock therapy (ALT) technique, modifying the way the microorganisms will interact with the surface of the material [13-15] and (ii) surface coating combining anti-adhesive and antimicrobial properties, as coating using formulations containing antifungal agents makes the surface resistant to infections and, in addition, to acting on the microorganism directly, can greatly reduce the adhesion of Candida spp. on this surface [15, 16]. Examples of this strategy are antifungal formulations containing polymers that form barrier films, since they polymerize and form a film in situ, giving adhesion and resistance, increasing the contact time of the antifungal agent, which allows greater action on the microbial cells $[17,18]$.

The clinical repercussions of Candida spp. biofilms are due to the high level of resistance, hindering the development of highly effective therapies. In addition to the relatively poor effectiveness of the available antifungal agents, another limitation is the minimal number of antifungal agents and their deficiencies in the pharmacokinetic/pharmacodynamic and toxicity profile. Thus, new formulations, novel antifungal agents, and/or the use of combination therapy, based mainly on broad spectrum polyenes, azole, and echinocandins, are necessary to increase the efficacy of fungal therapy $[1,5,19$, 20]. Approaches that seek to identify therapies that interfere with biofilm formation and/or maintenance may make it susceptible; this perspective may lead to combined therapies [20].
Since fungal biofilm is a difficult form of growth, the definition of the antifungal agent to control this structure should be rationally studied. Thus, the main objective of the present study is to make a rational choice of the best antifungal therapy for the in vitro treatment of the Candida spp. biofilm on venous catheters and, from it, propose an innovative formulation of a film-forming system, in order to prevent the formation of biofilms in the catheter through the coating strategy.

\section{Materials and methods}

\section{Strains:}

Three strains were used for each species selected in this study: C. albicans (CA CV42, CA CV44, CA DEB23), C. tropicalis (ATCC 750, CT 72A, CT RL104), and C. parapsilosis (ATCC 22019, CP RL27m, CP RL100). All these strains belong to the fungal collection of the Research Laboratory in Applied Mycology of Universidade Federal do Rio Grande do Sul (Porto Alegre, Brazil).

Antifungal agents: The antifungals used were anidulafungin (AND) (Pfizer®, New York, NY), fluconazole (FLZ) (Sigma-Aldrich, St. Louis, Missouri, USA), voriconazole (VRZ) (Pfizer®, New York, NY), ketoconazole (KTZ) (Cristália, Itapira, São Paulo, Brazil), and amphotericin B (AMB) (Cristália, Itapira, São Paulo, Brazil). The stock solution of FLZ was prepared in sterile distilled water, and the other antifungal agents were dissolved in DMSO (Sigma-Aldrich), so that when diluted in assay medium, a maximum concentration of DMSO of $2 \%$ in the assays was obtained. The solutions were prepared according to Clinical and Laboratory Standards Institute [21].

Fungal inoculum: Cultures of Candida cells grown for $24 \mathrm{~h}$ on Sabouraud Dextrose Agar (SDA) (HiMedia, Mumbai, India) at $35^{\circ} \mathrm{C}$ were resuspended in culture medium or other specific solution for each assay. The concentration is adjusted in spectrophotometer (GT220, Global Trade Technology) at $530 \mathrm{~nm}$ at a transmittance $(90 \%)$ equivalent to 0.5 of the McFarland Scale $\left(1.0-5.0 \times 10^{6}\right.$ colony forming units per $\mathrm{ml}-\mathrm{CFU} / \mathrm{ml}$ ).

Susceptibility of planktonic and sessile cells The sessile cells (isolated cells from biofilm) were obtained from biofilms formed on polyurethane central venous catheters (biofilm was formed according to "Catheter biofilm eradication" section. The minimum inhibitory concentration of planktonic cells (PMIC) and minimum inhibitory concentration of sessile cells (SMIC) were determined by the broth microdilution method according to protocol M27-A3 [21]. Concentrations capable of inhibiting $50 \%$ and $100 \%$ fungal growth of planktonic cells $\left(\mathrm{PMIC}_{50}\right.$ and $\mathrm{PMIC}_{100}$ ) and of sessile cells $\left(\mathrm{SMIC}_{50}\right.$ and $\mathrm{SMIC}_{100}$ ) were determined in order to assess the robustness of the activity of antifungal agents against both cell types. 


\section{Inhibition of biofilm formation (IBF)}

The ability of antifungal agents to inhibit biofilm formation in 96-well polystyrene microtiter plates was evaluated by the technique of Bachmann et al. and Pippi et al. with modifications [22, 23]. The wells of the microtiter plate were pretreated with antifungal solution in different concentration ranges, where they remained in contact for $48 \mathrm{~h}$ at a temperature of $4-8{ }^{\circ} \mathrm{C}$. Thereafter, the antifungal agents were removed from the wells of the plates and washed with sterile distilled water. The fungal inoculum was prepared in RPMI 1640 medium according to "Fungal inoculum" section. Then, this inoculum were added to each well of the plates along with RPMI 1640 medium $(1: 10 v / v)$ for biofilm formation and incubated in an oven for $48 \mathrm{~h}$ at $35^{\circ} \mathrm{C}$. Biofilm biomass was determined by the technique described by Stepanovic' et al., with modifications [24]. The reading was performed on a microplate reader (SpectraMax-M2; Molecular Devices ${ }^{\circledR}$, USA) at a wavelength of $450 \mathrm{~nm}$.

The concentrations able to inhibit $50 \%$ and $90 \%$ of biofilm formation were designated as $\mathrm{IBF}_{50}$ and $\mathrm{IBF}_{90}$, respectively. Inhibition was determined as a percentage relative to the untreated control (100\%) (according to the Eq. 1, where $A$ is the absorbance value) [23]. The assay was performed in triplicate.

$\mathrm{IBF}=\left[1-\left(\frac{A 450 \text { treated wells }}{A 450 \text { untreated wells }}\right)\right] \times 100$

\section{Biofilm removal (BR)}

The ability of antifungal agents to remove preformed biofilm in 96-well polystyrene microtiter plates was evaluated by the technique of Ramage et al. and Pippi et al. with some modifications $[23,25]$. The inoculum was prepared in $0.85 \%(\mathrm{w} / \mathrm{v})$ sterile saline solution (Dynamics, Diadema, São Paulo, Brazil) according to "Fungal inoculum" section, and biofilm formation was performed in the same way as in "Inhibition of biofilm formation (IBF)" section. The formed biofilms were treated with antifungal solutions at concentration ranges determined for each one. Plates containing the antifungal agents were incubated for $48 \mathrm{~h}$ at a temperature of $35^{\circ} \mathrm{C}$. Biofilm biomass was evaluated according to the technique described by Stepanović et al., with modifications [24]. The reading was performed on a microplate reader (SpectraMax-M2; Molecular Devices ${ }^{\circledR}$, USA) at a wavelength of $450 \mathrm{~nm}$.

Concentrations able to remove $50 \%$ and $90 \%$ of the preformed biofilm were designated as $\mathrm{BR}_{50}$ and $\mathrm{BR}_{90}$, respectively. Removal was determined as a percentage of the untreated control (100\%) (according to the Eq. 2, where $A$ is the absorbance value [23]. The assay was performed in triplicate.

$\mathrm{BR}=\left[1-\left(\frac{A 450 \text { treated biofilm }}{A 450 \text { untreated biofilm }}\right)\right] \times 100$

\section{Biofilm susceptibility (BMIC)}

The ability of antifungal agents to kill preformed biofilm cells in 96-well polystyrene microtiter plates was evaluated according to Ramage et al., Shuford et al., and Pippi et al. with modifications $[23,25,26]$. The performance of the test occurred according to "Inhibition of biofilm formation (IBF)" section, differing only in the final stage of staining. The reduction of the metabolic activity of preformed biofilms was estimated using the vital dye MTT [3-(4,5-dimethyl-thiazol-2yl)-2,5-diphenyl-tetrazolium bromide]. The reading was performed on a microplate reader (SpectraMax $\left.{ }^{\circledR}\right)$ at a wavelength of $570 \mathrm{~nm}$.

Concentrations able to reduce metabolic activity by $50 \%$ and $90 \%$ were designated as $\mathrm{BMIC}_{50}$ and $\mathrm{BMIC}_{90}$, respectively. The reduction of the metabolic activity of the treated biofilms was calculated as a percentage of untreated biofilms (100\%) (according to Eq. 3, where $A$ is the absorbance value) [23]. The assay was performed in triplicate.

$\mathrm{BMIC}=\left[1-\left(\frac{A 570 \text { treated biofilm }}{A 570 \text { untreated biofilm }}\right)\right] \times 100$

\section{Checkerboard test}

The effect of the association between AND and AMB on Candida biofilms was performed using the Checkerboard technique, according to Tobudic et al. with modifications [7]. The activity of inhibition, removal, and reduction of the metabolic activity of biofilms of the association in 96-well polystyrene microtiter plates proceeded according to "Inhibition of biofilm formation (IBF)," "Biofilm Removal (BR)", and "Biofilm Susceptibility (BMIC)" sections, respectively. Three strains were evaluated, one of each species: $\mathrm{CA}$ CV42, CT 72A, and CP RL27m. The assays were performed in triplicate. The fractional inhibitory concentration index (FICI) for each test was calculated according to the Eq. 4, where $\mathrm{Ac}$ and $\mathrm{Bc}$ are the concentrations of the antifungal agents in combination; $\mathrm{Aa}$ and $\mathrm{Ba}$ are the concentrations of the antifungal agents alone.

$\mathrm{FICI}=\left(\frac{\mathrm{Ac}}{\mathrm{Aa}}\right)+\left(\frac{\mathrm{Bc}}{\mathrm{Ba}}\right)$

For application of the formula, $\mathrm{IBF}_{90}, \mathrm{BR}_{50}$, and $\mathrm{BMIC}_{50}$ of the antifungal agents alone and in combination were used. The classification of the association was done according to Tobudic et al., through the index of fractional inhibitory concentration (FICI) [7]. When the FICI value is $>4$, the combination is considered antagonistic, when $>0.5$ and $\leq 4$, it is considered indifferent, and when $\leq 0.5$, it is considered to be synergistic. 


\section{Inhibition of biofilm formation in catheter}

The ability of antifungal agents to inhibit biofilm formation in a new polyurethane central venous catheter (Arrow International, Teleflex Medical, Athlone, Ireland) was evaluated. Sterile catheter samples of $1 \mathrm{~cm}$ length were placed in tubes containing antifungal agents in solution, in fixed concentrations, and predetermined for each, for a period of $24 \mathrm{~h}$ at a temperature of $4-8^{\circ} \mathrm{C}$. The preparation of the inoculum was performed according to "Fungal inoculum" section in peptone water. Then, this fungal suspension was transferred to a tube containing peptone water $(1: 10 \mathrm{v} / \mathrm{v})$. The catheter samples were taken from the antifungal solution, washed with sterile water, and were added to the tube containing the inoculum and incubated for $48 \mathrm{~h}$ at a temperature of $35^{\circ} \mathrm{C}$. After, the catheters were washed with sterile water to remove the nonadherent cells, placed in another tube containing sterile water, and incubated in an ultrasound bath (USC-700; UNIQUE, São Paulo, Brazil) for $20 \mathrm{~min}$ at a power of $40 \mathrm{KHz}$, to detach the adhered cells. The same procedures were performed for the catheter that was exposed to the solution without the presence of antifungal agent (untreated control). Then, $10 \mu \mathrm{l}$ of each tube were drawn and tenfold serial dilutions (up to $10^{-4}$ ) were made. Then, $10 \mu \mathrm{l}$ directly from the tube containing the catheter and $10 \mu \mathrm{l}$ of each dilution were seeded on SDA plates and incubated for $24 \mathrm{~h}$ at a temperature of $35^{\circ} \mathrm{C}$. Subsequently, the $\mathrm{CFU} / \mathrm{cm}^{2}$ of catheter and percent inhibition of biofilm formation compared to the untreated control were determined. This trial was performed in triplicate.

\section{Catheter biofilm eradication}

The ability of antifungal agents to remove the preformed biofilm in a new polyurethane central venous catheter and its action on the removed cells was evaluated. The assay was performed according to "Inhibition of biofilm formation in catheter" section; however, the biofilm was first formed in the material and after treated with the antifungal agents for $48 \mathrm{~h}$ at $35^{\circ} \mathrm{C}$. The catheter samples were placed in tubes containing sterile water and incubated in an ultrasound bath for $20 \mathrm{~min}$ at a power of $40 \mathrm{KHz}$ to detach the adhered cells. The same procedures were performed for the untreated controls. From the solutions containing the antifungal agents and water tubes containing the catheter samples, $10 \mu \mathrm{L}$ were withdrawn and tenfold serial dilutions (up to $10^{-4}$ ) were made. Then, $10 \mu$ directly from the tubes (antifungal and water with the catheter) and $10 \mu \mathrm{L}$ of each dilution were seeded on SDA plates and incubated for $24 \mathrm{~h}$ at a temperature of $35^{\circ} \mathrm{C}$. Subsequently, the $\mathrm{CFU} / \mathrm{cm}^{2}$ of the catheter and the percentage of biofilm eradication were determined in relation to the control without treatment (100\%). The assay was performed in triplicate.

\section{Inhibition and eradication of catheter biofilms of the antifungal agents association}

The tests were performed according to "Inhibition of biofilm formation in catheter" and "Catheter biofilm eradication" sections, respectively, testing fixed concentrations of AND $\left(0.5 \mu \mathrm{g} \mathrm{mL}^{-1}\right)$, AMB $\left(2.5 \mu \mathrm{g} \mathrm{m}^{-1}\right)$, and AND/AMB $(0.5 /$ $2.5 \mu \mathrm{g} \mathrm{mL}^{-1}$. The assays were performed in triplicate.

\section{Antibiofilm activity of the antifungals incorporated in a film-forming system}

This system consists of a hydrogel with low viscosity, which, in situ, forms a film, increasing contact time $[18,27]$. The film-forming system for use in catheter coating, in order to prevent the formation of biofilm, was prepared by dissolving the antifungal agents in DMSO. Then, the antifungal agent was added to an aqueous solution of Carbopol ${ }^{\circledR} 980$ polymer (Wickliffe, Ohio, USA) and Pullulan (Corn Products, São Paulo, Brazil) under magnetic stirring for homogenization. Pullulan is a polysaccharide with excellent film-forming properties [28]. After, the $\mathrm{pH}$ was adjusted to 5.0-6.0 (as the skin) using a $9 \% \mathrm{NaOH}$ solution (Table 1). A film-forming system, hydrogel type, was obtained in final concentration: AND $\left(0.5 \mu \mathrm{g} \mathrm{mL}^{-1}\right.$ and $\left.1 \mu \mathrm{g} \mathrm{mL}^{-1}\right), \operatorname{AMB}\left(2.5 \mu \mathrm{g} \mathrm{mL}^{-1}\right)$, and AND/AMB $\left(0.5 / 2.5 \mu \mathrm{g} \mathrm{mL}^{-1}\right)$. The ability to inhibit biofilm formation was tested in a catheter according to "Inhibition of biofilm formation in catheter" section, with modifications. The contact time of the catheter with the formulation was $10 \mathrm{~min}$, after which the catheter was removed and left at room temperature for $30 \mathrm{~min}$, until the formulation dried and formed a film overlaying the material. Three strains were evaluated, one of each species: CA CV42, CT 72A, and CP RL27m. The assay was performed in triplicate.

\section{Characterization of the film forming system}

The most effective formulations were characterized by drying time, stickiness, and surface coating. Drying time was performed according to Schroeder et al., Paradkar et al., Kathe and Kathpali, and Tran and Tran (2019) with modifications [29-32]. The objective was to evaluate whether the addition of antifungal agents to the formulations altered the time required for drying the coating and, consequently, film formation on the catheter surface. After drying of the film, the stickiness was determined according to Schroeder et al., Paradkar et al., Kathe and Kathpali, and Tran and Tran with modifications [29-32]. The objective was to evaluate if the film, after drying, presents some degree of external adhesion to the device. The assays were performed in triplicate. Differences in the morphology of the catheter surface coating by the formulations (AND $1 \mu \mathrm{g} \mathrm{mL}^{-1}$; AND/AMB; control sample without coating and coated with the formulation without addition of 
Table 1 Composition of the film-forming system formulation

Formulations tested Components

\begin{tabular}{lllllll}
\hline Pullulan $\left(\mathrm{mg} \mathrm{mL}^{-1}\right)$ & Carbopol $980\left(\mathrm{mg} \mathrm{mL}^{-1}\right)$ & DMSO $(\%)$ & $\mathrm{NaOH} 9 \%$ & Antifungal agent $\left(\mu \mathrm{mL}^{-1}\right)$ & Ultrapure water \\
\cline { 1 - 4 } & & & & AND & AMB & \\
20 & 0.65 & 0.5000 & q.s & - & - & q.s \\
20 & 0.65 & 0.0625 & q.s & 0.5 & - & q.s \\
20 & 0.65 & 0.1250 & q.s & 1 & - & q.s \\
20 & 0.65 & 0.1000 & q.s & - & 2.5 & q.s \\
& 0.65 & 0.1625 & q.s & 0.5 & 2.5 & q.s \\
\hline
\end{tabular}

Control, formulation without antifungal agent; $A N D^{\mathrm{a}}$, anidulafungin $\left(0.5 \mu \mathrm{g} \mathrm{mL} \mathrm{L}^{-1}\right) ; A N D^{\mathrm{b}}$, anidulafungin $\left(1 \mu \mathrm{g} \mathrm{mL} \mathrm{L}^{-1}\right) ; A M B$, amphotericin B $\left(2.5 \mu \mathrm{g} \mathrm{mL}^{-1}\right)$; AND/AMB, association of anidulafungin and amphotericin $\mathrm{B}\left(0.5 / 2.5 \mu \mathrm{g} \mathrm{mL}^{-1}\right)$

Preparation: carbopol and pullulan were dispersed in water with a magnetic stirrer. Then, the antifungal agent was solubilized in DMSO and added to the aqueous solution. $\mathrm{pH}$ was adjusted to 5.0-6.0 with a solution containing $9 \%$ of $\mathrm{NaOH}$

antifungal agent) were evaluated by scanning electron microscopy. The catheter sample coated with each formulation was desiccated at critical point and sprayed with gold, and micrographs were obtained by scanning electron microscopy (JSM 6060).

\section{Statistical analysis}

In cases where there were three groups to be compared (activity $50 \%, 90 \%$, and control), the Levene test was applied, with significant $p<0.05$. Then, when $p>0.05$, the data were analyzed by means of the one-way ANOVA and for the cases where $p<0.05$, the analysis was done through the KruskalWallis test, considering significant $p<0.05$. The post tests used were the Tukey multiple comparison test and the Dunn multiple comparison test, respectively. Mann-Whitney test was also used in cases where there were two groups $(50 \%$ activity and control). The analyses were performed using the IBM SPSS Statistics 18 software.

\section{Results}

The methodological flow to follow each step and the subsequent step can be observed in Fig. 1. The concentrations of SMIC50 and SMIC100 determined in this study showed, in general, differences in comparison with PMIC50 and PMIC100, respectively. The reading was performed according to document M27-A3 (CLSI, 2008) both for planktonic cells and for sessile cells, for comparison purposes (Table 2).

AND and AMB were the most potent drugs in the biofilms assays, such as IBF and treatment of preformed biofilm, BF and BMIC, evaluated in 96-well polystyrene microtiter plates. Surface pretreatment with AND and AMB was effective, inhibiting more than $90 \%$ of the biofilm formation, in a concentration range of $0.125-2 \mu \mathrm{g} \mathrm{mL}^{-1}$ and $1-40 \mu \mathrm{g} \mathrm{mL} \mathrm{m}^{-1}$, respectively. Treatment of the preformed biofilm required higher concentrations, so that more than $90 \%$ could be removed or significant reduction of metabolic activity can be observed (>90\%). AND, to a part of the strains, was able to remove more than $90 \%$ of the biofilm and to reduce more than $90 \%$ of the metabolic activity of the biofilm, in concentrations in the range of $1-2 \mu \mathrm{g} \mathrm{mL}^{-1}$ and $0.125-2 \mu \mathrm{g} \mathrm{mL}^{-1}$, respectively. The same pattern was observed for AMB in concentrations of $4-40 \mu \mathrm{g} \mathrm{mL}^{-1}$ and $1-40 \mu \mathrm{g} \mathrm{mL}^{-1}$, respectively (Table 2).

To determine if it would be possible to optimize the activity of the two antifungals with the best results obtained in 96-well polystyrene microtiter plates, AND and AMB, we tested the effectiveness of their combination, AND $\left(2 \mu \mathrm{g} \mathrm{mL}^{-1}\right)$ and AMB $\left(20 \mu \mathrm{g} \mathrm{mL}^{-1}\right)$, evaluating $\mathrm{IBF}_{90}, \mathrm{BR}_{50}$, and $\mathrm{BMIC}_{50}$. The association had a FICI of less than 0.5 , in the three tests for all strains, indicating a synergistic activity of this combination (Supplementary Table 1).

The action of antifungal agents on biofilms formed in central venous catheters was superior to that evaluated in 96-well polystyrene microtiter plates (Table 3 and Table 2, respectively). AND, in the evaluation of biofilm inhibition, showed $100 \%$ activity for all strains. When biofilm eradication was evaluated, $100 \%$ activity was observed for almost all strains, being the only exception, the strain RL27m (99.64\%). In the evaluation of the inhibition for the other antifungal agents, there was a wide variation among the strains, with high activity of AMB (79.19-100\%), VRZ (78.16-100\%), and KTZ (79.73-100\%). FLZ was less effective and with wide variation in relation to other antifungal agents (50-99.74\%). When we referred to the eradication of the preformed biofilm, the variation was lower, however, the high activity trend of AMB (81.13-100\%), VRZ (97.24-100\%), and KTZ (95.88$99.84 \%$ ). FLZ again presented lower performance and, again, greater variability in relation to the others $(81.82-100 \%)$ (Table 4). 


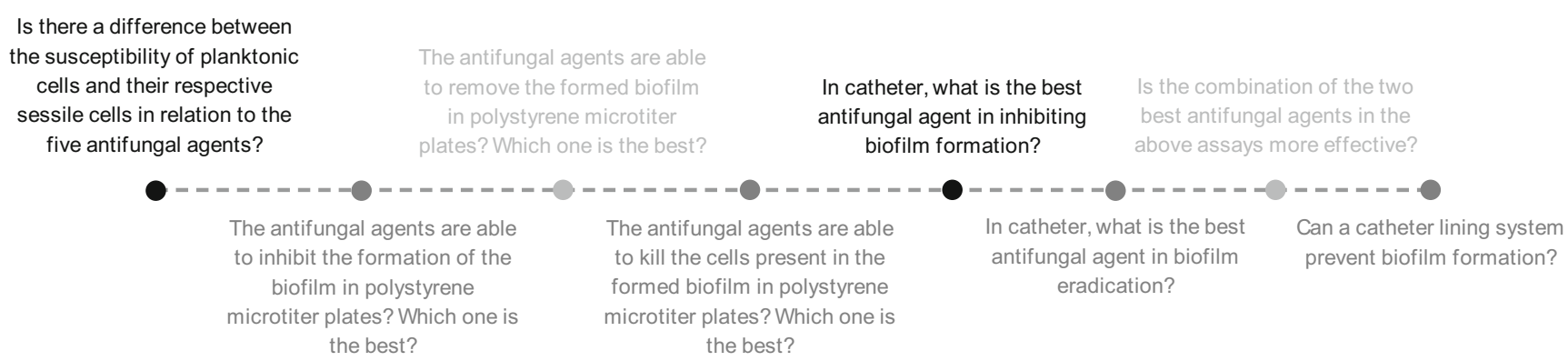

Fig. 1 Methodological flowchart: rational selection of antifungal agents

The activity in catheter-formed biofilms using the combination of antifungal agents, AND and AMB, at lower concentrations, demonstrated a considerable increase in the antifungal activity compared to the isolated agents. Meanwhile, AND at a concentration of $0.5 \mu \mathrm{g} \mathrm{mL}^{-1}$ inhibited $37.88-75.96 \%$ and eradicated $69.71-96.97 \%$ of the biofilms. The AND tested alone at $1 \mu \mathrm{g} \mathrm{mL}^{-1}$ inhibited $100 \%$ and eradicated 99.64 $100 \%$ of the biofilm. The AMB used without association showed inhibition of biofilm formation in a range of 49.78 $68.12 \%$ and eradication between 61.84 and $96.81 \%$. When antifungal agents (AND/AMB $-0.5 / 2.5 \mu \mathrm{g} \mathrm{mL}^{-1}$ ) were associated, inhibition of the biofilm was $94.89-100 \%$ and eradication thereof was concentrated in the range of $99.08-100 \%$ (Table 4). The same tendency is observed when the same antifungal agents, in the same concentrations, are incorporated into a film-forming system formulation and their effectiveness in inhibiting biofilm is evaluated. While AND without association, at a concentration of $0.5 \mu \mathrm{g} \mathrm{mL}{ }^{-1}$, inhibited 49.58 $70.12 \%$, and at a concentration of $1 \mu \mathrm{g} \mathrm{mL}^{-1}$, the inhibition was $90.50-98.26 \%$. On the other hand, AMB had a lower performance, with inhibition within the range of 37.71-73.49\%. Again, the association demonstrated superior outcome, with significant inhibition efficacy, in a range of 93.41-98.26\% and low coefficient of variation, different from the others, which presented high coefficients of variation (Table 4).

The time required to dry the catheter surface coating and film formation occurred within 25 min for both formulation without addition of antifungal agents and for those containing AND $1 \mu \mathrm{g} \mathrm{mL}^{-1}$ and AND/AMB (Supplementary Fig 1). Likewise, the stickiness of the formulation was not changed with the addition of antifungal agents, a few cotton fibers adhered after drying for all films (with and without antifungal agents), with variations between the triplicates of $0-2$ adhered cotton fibers, representing low density of adhered fibers (Supplementary Fig 2). Scanning electron microscopy showed that the uncoated catheter presents surface with subtle porosity (Fig. 2a). The coating material of the formulation without the addition of antifungal agents presented layers, covering these pores (Fig.2b). In the formulations with AND and $\mathrm{AND} / \mathrm{AMB}$, it was possible to observe the formation of interconnected networks on the device surface (Fig. 2c, d, respectively).

\section{Discussion}

Biofilms formed by Candida species represent an important and serious clinical problem, mainly related to medical devices. Currently, considering the absence of approved biofilm-specific drugs, the recommendation is to remove infected devices when biofilm infection is suspected. However, this is not always feasible, and antimicrobial treatment may be necessary $[11,12,33]$. New strategies to combat these forms of microbial development are needed. For instance, we emphasize the use of currently available antifungal agents in new drug delivery systems, in order to maximize the efficiency of the therapy, reducing the biofilm formation and the costs of long periods of hospitalization [11, 34, 35].

As an initial part of screening for antifungal agents, the determination of the PMICs and SMICs of the antifungal agents against the evaluated strains allowed us to observe the difference between some profiles of susceptibility of planktonic cells in relation to their respective sessile cells against the antifungal agents, even if only for some strains. Thus, the strong tendency of sessile cells to be less susceptible to antifungal agents, although similar profiles can also be found [8, 36-38].

Knowing that biofilm is associated with severe prognosis, since this form of growth is highly recalcitrant to treatments, the choice of therapy and management strategy to be used should be studied and rationally selected. Based on this assumption, the initial screening of antifungal performance was performed by testing using polystyrene microtiter plates, as the technique is well known and used in the literature, is fast, inexpensive, easy to use, accurate, and reproducible for susceptibility testing of Candida spp. biofilms. This evaluation is benefited by its use coupled with a colorimetric method [25]. The results obtained with polystyrene microtiter plates were also used as a differentiated type of material to be compared with the main study material, polyurethane. We evaluated the same action parameters against biofilm as those used for the catheter (biofilm inhibition and removal). The incubation of antifungal agents in the microplates works similarly to the antimicrobial lock therapy technique on catheter. Surface impregnation can inhibit fungal cell adhesion and also cause direct inhibitory activity through the release of the drug from 
Table 2 Effects of antifungal agents on planktonic and sessile cells and biofilms of Candida spp

\begin{tabular}{|c|c|c|c|c|c|c|c|c|c|c|c|}
\hline \multirow[t]{3}{*}{ Test } & \multirow[t]{3}{*}{ Strains } & \multicolumn{10}{|c|}{ Concentration $\left(\mu \mathrm{g} \mathrm{mL}^{-1}\right)$} \\
\hline & & \multicolumn{2}{|l|}{ AND } & \multicolumn{2}{|l|}{ FLZ } & \multicolumn{2}{|l|}{ VRZ } & \multicolumn{2}{|l|}{ KTZ } & \multicolumn{2}{|l|}{$\mathrm{AMB}$} \\
\hline & & $\mathrm{PMIC}_{50}$ & $\mathrm{PMIC}_{100}$ & $\mathrm{PMIC}_{50}$ & $\mathrm{PMIC}_{100}$ & $\mathrm{PMIC}_{50}$ & $\mathrm{PMIC}_{100}$ & $\mathrm{PMIC}_{50}$ & $\mathrm{PMIC}_{100}$ & $\mathrm{PMIC}_{50}$ & $\mathrm{PMIC}_{100}$ \\
\hline \multirow[t]{9}{*}{ Susceptibility of planktonic cells } & $\mathrm{CA} \mathrm{CV} 42$ & 0.00098 & 0.00780 & 16 & 64 & 0.12500 & 2 & 0.06250 & 32 & 0.06250 & 0.12500 \\
\hline & $\mathrm{CA} \mathrm{CV} 44$ & 0.00098 & 0.01560 & 4 & $>256$ & 0.25000 & $>64$ & 2 & 32 & 0.03125 & 0.12500 \\
\hline & CA DEB23 & 0.00098 & 0.01560 & 16 & $>256$ & 8 & $>64$ & 0.12500 & 32 & 0.03125 & 0.12500 \\
\hline & ATCC 750 & 0.00195 & 0.01560 & 1 & 8 & 0.12500 & 1 & 0.06250 & 8 & 0.06250 & 0.25000 \\
\hline & CT 72A & 0.00195 & 0.00391 & 8 & 128 & 0.03125 & 0.25000 & 0.12500 & 4 & 0.06250 & 0.50000 \\
\hline & CT RL104 & 0.00098 & 0.00391 & 2 & 8 & 0.50000 & 4 & 4 & 16 & 0.12500 & 0.50000 \\
\hline & ATCC 22019 & 0.06250 & 0.25000 & 4 & 8 & 0.03125 & 0.12500 & 0.12500 & 0.5 & 0.06250 & 0.50000 \\
\hline & CP RL27m & 0.06250 & 0.12500 & 64 & 128 & 0.50000 & 2 & 0.12500 & 1 & 0.06250 & 0.50000 \\
\hline & CP RL100 & 0.01560 & 0.03125 & 2 & 32 & 0.06250 & 0.12500 & 0.12500 & 2 & 0.06250 & 0.25000 \\
\hline \multirow[t]{10}{*}{ Susceptibility of sessile cells } & & $\mathrm{SMIC}_{50}$ & $\mathrm{SMIC}_{100}$ & $\mathrm{SMIC}_{50}$ & $\mathrm{SMIC}_{100}$ & $\mathrm{SMIC}_{50}$ & $\mathrm{SMIC}_{100}$ & $\mathrm{SMIC}_{50}$ & $\mathrm{SMIC}_{100}$ & $\mathrm{SMIC}_{50}$ & $\mathrm{SMIC}_{100}$ \\
\hline & $\mathrm{CA} \mathrm{CV} 42$ & 0.00195 & 0.01560 & 16 & $>256$ & 0.12500 & $>64$ & 8 & 32 & 0.12500 & 0.25000 \\
\hline & $\mathrm{CA} \mathrm{CV} 44$ & 0.00195 & 0.01560 & 16 & $>256$ & 4 & $>64$ & 16 & 32 & 0.12500 & 0.25000 \\
\hline & CA DEB23 & 0.00391 & 0.03125 & 128 & $>256$ & 32 & $>64$ & 4 & 32 & 0.06250 & 0.25000 \\
\hline & ATCC 750 & 0.00781 & 0.03125 & 4 & 32 & 0.5 & 64 & 0.12500 & 8 & 0.12500 & 0.25000 \\
\hline & CT 72A & 0.00391 & 0.01560 & 32 & 256 & 0.06250 & 0.25000 & 0.50000 & 4 & 0.06250 & 0.25000 \\
\hline & CT RL104 & 0.00195 & 0.01560 & 4 & 64 & 4 & 32 & 1 & 16 & 0.12500 & 0.50000 \\
\hline & ATCC 22019 & 0.12500 & 0.50000 & 4 & 16 & 0.06250 & 0.25000 & 0.12500 & 0.50000 & 0.12500 & 0.50000 \\
\hline & CP RL27m & 0.06250 & 0.12500 & 64 & 128 & 0.5 & 1 & 0.12500 & 1 & 0.06250 & 1 \\
\hline & CP RL100 & 0.06250 & 0.12500 & 32 & 256 & 0.06250 & 0.25000 & 0.25000 & 4 & 0.25000 & 1 \\
\hline \multirow[t]{10}{*}{ Inhibition of biofilm formation } & & $\mathrm{IBF}_{50}$ & $\mathrm{IBF}_{90}$ & $\mathrm{IBF}_{50}$ & $\mathrm{IBF}_{90}$ & $\mathrm{IBF}_{50}$ & $\mathrm{IBF}_{90}$ & $\mathrm{IBF}_{50}$ & $\mathrm{IBF}_{90}$ & $\mathrm{IBF}_{50}$ & $\mathrm{IBF}_{90}$ \\
\hline & CA CV42 & 0.01560 & 0.25000 & 64 & $>640$ & 2 & $>40$ & 16 & $>320$ & 0.25000 & 4 \\
\hline & CA CV44 & 0.03125 & 0.50000 & 128 & $>640$ & 4 & $>40$ & 32 & $>320$ & 0.50000 & 20 \\
\hline & CA DEB23 & 0.06250 & 0.50000 & 64 & $>640$ & 2 & $>40$ & 16 & $>320$ & 0.25000 & 4 \\
\hline & ATCC 750 & 0.00781 & 0.12500 & 64 & $>640$ & 0.5 & 40 & 32 & $>320$ & 0.06250 & 1 \\
\hline & CT 72A & 0.01560 & 0.25000 & 320 & $>640$ & 1 & $>40$ & 320 & $>320$ & 0.12500 & 4 \\
\hline & CT RL104 & 0.00781 & 0.25000 & 320 & $>640$ & 1 & $>40$ & 320 & $>320$ & 0.25000 & 2 \\
\hline & ATCC 22019 & 0.12500 & 2 & 256 & $>640$ & 0.25000 & $>40$ & 8 & $>320$ & 0.25000 & 4 \\
\hline & CP RL27m & 0.12500 & $>2$ & $>640$ & $>640$ & 2 & $>40$ & 320 & $>320$ & 2 & 40 \\
\hline & CP RL100 & 0.12500 & 1 & 256 & $>640$ & 0.5 & $>40$ & 32 & $>320$ & 1 & 20 \\
\hline \multirow[t]{10}{*}{ Biofilm removal } & & $\mathrm{BR}_{50}$ & $\mathrm{BR}_{90}$ & $\mathrm{BR}_{50}$ & $\mathrm{BR}_{90}$ & $\mathrm{BR}_{50}$ & $\mathrm{BR}_{90}$ & $\mathrm{BR}_{50}$ & $\mathrm{BR}_{90}$ & $\mathrm{BR}_{50}$ & $\mathrm{BR}_{90}$ \\
\hline & CA CV42 & 1 & $>2$ & 640 & $>640$ & 8 & $>40$ & 320 & $>320$ & 2 & $>40$ \\
\hline & $\mathrm{CA} \mathrm{CV} 44$ & 2 & $>2$ & $>640$ & $>640$ & 20 & $>40$ & $>320$ & $>320$ & 8 & $>40$ \\
\hline & CA DEB23 & 1 & $>2$ & $>640$ & $>640$ & 2 & $>40$ & 16 & $>320$ & 8 & $>40$ \\
\hline & ATCC 750 & 0.06250 & 1 & 128 & $>640$ & 1 & $>40$ & 160 & $>320$ & 0.12500 & 4 \\
\hline & CT 72A & 0.25 & 2 & $>640$ & $>640$ & 2 & $>40$ & $>320$ & $>320$ & 0.50000 & 8 \\
\hline & CT RL104 & 0.12500 & 1 & $>640$ & $>640$ & 4 & $>40$ & $>320$ & $>320$ & 1 & 8 \\
\hline & ATCC 22019 & 0.25000 & 2 & 320 & $>640$ & 1 & $>40$ & 160 & $>320$ & 1 & 20 \\
\hline & CP RL27m & 0.50000 & $>2$ & $>640$ & $>640$ & 4 & $>40$ & $>320$ & $>320$ & 4 & $>40$ \\
\hline & CP RL100 & 0.50000 & $>2$ & 640 & $>640$ & 2 & $>40$ & 160 & $>320$ & 2 & 40 \\
\hline \multirow[t]{10}{*}{ Susceptibility of biofilms } & & $\mathrm{BMIC}_{50}$ & $\mathrm{BMIC}_{90}$ & $\mathrm{BMIC}_{50}$ & $\mathrm{BMIC}_{90}$ & $\mathrm{BMIC}_{50}$ & $\mathrm{BMIC}_{90}$ & $\mathrm{BMIC}_{50}$ & $\mathrm{BMIC}_{90}$ & $\mathrm{BMIC}_{50}$ & $\mathrm{BMIC}_{90}$ \\
\hline & $\mathrm{CA} \mathrm{CV} 42$ & 0.25000 & 2 & 640 & $>640$ & 4 & $>40$ & 160 & $>320$ & 2 & 40 \\
\hline & $\mathrm{CA} \mathrm{CV} 44$ & 0.25000 & $>2$ & 640 & $>640$ & 8 & $>40$ & 320 & $>320$ & 2 & $>40$ \\
\hline & CA DEB23 & 0.25000 & 2 & 640 & $>640$ & 0.50000 & 40 & 4 & 320 & 2 & 40 \\
\hline & ATCC 750 & 0.01560 & 0.12500 & 32 & 640 & 0.50000 & 40 & 16 & 320 & 0.06250 & 1 \\
\hline & СТ 72A & 0.01560 & 0.12500 & 256 & $>640$ & 1 & $>40$ & 160 & $>320$ & 0.25000 & 4 \\
\hline & CT RL104 & 0.03125 & 0.25000 & 320 & $>640$ & 4 & $>40$ & 320 & $>320$ & 0.50000 & 8 \\
\hline & ATCC 22019 & 0.06250 & 2 & 256 & $>640$ & 0.25000 & 40 & 4 & 320 & 0.25000 & 2 \\
\hline & CP RL27m & 0.25000 & $>2$ & $>640$ & $>640$ & 2 & $>40$ & 32 & $>320$ & 2 & $>40$ \\
\hline & CP RL100 & 0.12500 & 1 & 128 & $>640$ & 1 & 20 & 8 & 320 & 0.50000 & 4 \\
\hline
\end{tabular}

$A N D$, anidulafungin; $F L Z$, fluconazole; $V R Z$, voriconazole; $K T Z$, ketoconazole; $A M B$, amphotericin $\mathrm{B}$.

CA, C. albicans; $C P, C$. parapsilosis; $C T, C$. tropicalis

$P_{M I C_{50}}$ and $P M I C_{100}$, minimum concentration inhibitors able to inhibit $50 \%$ and $100 \%$ of the planctonic cells respectively

$S M I C_{50}$ and $S M I C_{100}$, minimum concentration inhibitors able to inhibit $50 \%$ and $100 \%$ of the sessile cells respectively

$I B F_{50}$ and $I B F_{90}$, concentration able to inhibit $50 \%$ and $90 \%$ of biofilm formation respectively

$B R_{50}$ and $B R_{90}$, concentration able to remove $50 \%$ and $90 \%$ of the formed biofilm respectively

$B M I C_{50}$ and $B M I C_{90}$, concentration able to inhibit $50 \%$ and $90 \%$ of the biofilm cellular metabolism, respectively 
Table 3 Effects of antifungal agents on Candida biofilms in central venous polyurethane catheter surface

\begin{tabular}{|c|c|c|c|c|c|c|}
\hline \multirow[t]{2}{*}{ Test } & \multirow[t]{2}{*}{ Strains } & \multicolumn{5}{|c|}{ Biofilm Activity (\%) } \\
\hline & & AND & FLZ & VRZ & KTZ & AMB \\
\hline \multirow[t]{9}{*}{ Inhibition of biofilm formation } & $\mathrm{CA} \mathrm{CV} 42$ & 100 & 97.97 & 100 & 100 & 100 \\
\hline & $\mathrm{CA} \mathrm{CV} 44$ & 100 & 50.00 & 78.16 & 89.47 & 98.68 \\
\hline & CA DEB23 & 100 & 93.73 & 97.98 & 97.46 & 99.96 \\
\hline & ATCC 750 & 100 & 100 & 100 & 93.24 & 100 \\
\hline & CT 72A & 100 & 69.84 & 79.69 & 99.62 & 97.91 \\
\hline & CT RL104 & 100 & 99.31 & 98.51 & 99.56 & 100 \\
\hline & ATCC 22019 & 100 & 96.83 & 99.98 & 99.98 & 90.36 \\
\hline & CP RL27m & 100 & 99.74 & 100 & 99.67 & 79.19 \\
\hline & CP RL100 & 100 & 92.95 & 97.65 & 79.73 & 98.72 \\
\hline Average & & 100 & 88.93 & 94.66 & 95.41 & 96.09 \\
\hline Coefficient of variation & & 0 & 19.52 & 9.49 & 7.27 & 7.32 \\
\hline \multirow[t]{9}{*}{ Biofilm eradication } & $\mathrm{CA} \mathrm{CV} 42$ & 100 & 89.54 & 100 & 98.95 & 99,99 \\
\hline & $\mathrm{CA} \mathrm{CV} 44$ & 100 & 81.82 & 99.93 & 99.89 & 100 \\
\hline & CA DEB23 & 100 & 98.40 & 100 & 95.88 & 100 \\
\hline & ATCC 750 & 100 & 99.79 & 100 & 99.79 & 100 \\
\hline & CT 72A & 100 & 99.82 & 99.45 & 99.90 & 100 \\
\hline & CT RL104 & 100 & 99.04 & 99.65 & 99.76 & 99.36 \\
\hline & ATCC 22019 & 100 & 100 & 100 & 99.94 & 100 \\
\hline & CP RL27m & 99.64 & 82.17 & 97.24 & 99.37 & 98.95 \\
\hline & CP RL100 & 100 & 90.56 & 99.94 & 99.92 & 81.13 \\
\hline Average & & 99.96 & 93.46 & 99.58 & 99.26 & 97.70 \\
\hline Coefficient of variation & & 0.12 & 8.16 & 0.90 & 1.32 & 6.38 \\
\hline
\end{tabular}

Biofilm activity (\%): percentage of inhibition compared to the control. $A N D$, anidulafungin $\left(1 \mu \mathrm{g} \mathrm{mL} L^{-1}\right) ; F L Z$, fluconazole $\left(256 \mu \mathrm{g} \mathrm{mL}{ }^{-1}\right) ; V R Z$, voriconazole $\left(8 \mu \mathrm{g} \mathrm{mL} L^{-1}\right) ; K T Z$, ketoconazole $\left(32 \mu \mathrm{g} \mathrm{mL} L^{-1}\right) ; A M B$, amphotericin B $\left(8 \mu \mathrm{g} \mathrm{mL}^{-1}\right)$

CA, C. albicans; CP, C. parapsilosis; CT, C. tropicalis

$\mathrm{CFU}$ colony-forming units

the material [13]. The comparison is important, since different materials/surfaces have significant influence on the architecture, morphology, and thickness of the biofilm formed and, thus, on its susceptibility profile $[39,40]$. Therefore, this comparison of both materials was used to evaluate the robustness of the performance of these antifungal agents.

The biofilm composition of Candida spp. formed in polystyrene microtiter plates shows differences related to the species, as structure, composition, and adhesion proteins $[8,39$, 41-43], reflecting as differences in susceptibility to antifungal agents. Biofilms of $C$. albicans were less susceptible, mainly in relation to the removal and reduction of metabolic activity. These biofilms are composed of an intricate mesh of yeast cells, hyphae, and pseudo-hyphae, forming multiple layers $[39,42]$. Thus, taking into account their density, complexity, and organization, a greater difficulty for antifungal agents to act on this structure was already expected. We observed, all biofilms were more susceptible to AND and AMB. The use of combined antifungal therapies can help in combating these structures, but is not yet recommended in the clinic $[1,7$,
20]. AND and AMB presented the best results on biofilms, for this reason, we tested its association in 96-well microtiter plates in order to analyze the possibility of further improving the action of both, for the purpose of evaluating whether it would be possible to reduce the concentrations and maintain their activity $[44,45]$. Combination showed FICI less than 0.5 , for the three strains tested, indicating a synergistic combination. Valentín et al. demonstrated a reduction in the required concentration of AND when combined with AMB for five Candida spp. species [46].

Fungal biofilm susceptibility evaluation in polyurethane central venous catheters was studied through two approaches: one of the most common in the management of these catheterrelated infections, such as antibiotic lock therapy (ALT), and the treatment of the already formed biofilm [37].

The possibility of using ALT, especially in situations where it is recommended, has growing clinical evidence of success, and is currently recommended and used in the treatment of infections of the bloodstream associated with catheterization, according to the guidelines of the Infectious Diseases Society 
Table 4 Effects of antifungal agents alone and in combination, in solution, and in a formulation of a film-forming system on Candida spp. biofilms in central venous polyurethane catheter surface

\begin{tabular}{|c|c|c|c|c|c|c|c|c|c|}
\hline \multirow[t]{3}{*}{ Test } & \multirow[t]{3}{*}{ Strains } & \multicolumn{8}{|c|}{ Biofilm activity (\%) } \\
\hline & & \multicolumn{4}{|c|}{ Solution } & \multicolumn{4}{|c|}{ Film-forming system } \\
\hline & & $\mathrm{AND}^{\mathrm{a}}$ & $\mathrm{AND}^{\mathrm{b}}$ & AMB & $\begin{array}{l}\text { AND/ } \\
\text { AMB }\end{array}$ & $\mathrm{AND}^{\mathrm{a}}$ & $\mathrm{AND}^{\mathrm{b}}$ & AMB & $\begin{array}{l}\text { AND/ } \\
\text { AMB }\end{array}$ \\
\hline \multirow[t]{3}{*}{ Inhibition of biofilm formation } & $\mathrm{CA} \mathrm{CV} 42$ & 37.88 & 100 & 59.00 & 100 & 70.12 & 98.26 & 64.85 & 98.26 \\
\hline & CT 72A & 52.70 & 100 & 49.78 & 94.89 & 49.58 & 90.50 & 37.71 & 93.41 \\
\hline & CP RL27m & 75.96 & 100 & 68.12 & 95.13 & 60.37 & 92.54 & 73.49 & 94.62 \\
\hline Average & & 63.88 & 100 & 58.97 & 96.67 & 60.03 & 93.77 & 58.68 & 95.43 \\
\hline Coefficient of variation & & 18.25 & 0 & 15.55 & 2.98 & 17.12 & 4.29 & 31.81 & 2.64 \\
\hline \multirow[t]{3}{*}{ Biofilm eradication } & $\mathrm{CA} \mathrm{CV} 42$ & 96.97 & 100 & 96.81 & 100 & - & - & - & - \\
\hline & CT 72A & 69.71 & 100 & 61.84 & 99.91 & - & - & - & - \\
\hline & CP RL27m & 94.46 & 99.64 & 93.90 & 99.08 & - & - & - & - \\
\hline Average & & 87.05 & 99.96 & 84.18 & 99.66 & - & - & - & - \\
\hline Coefficient of variation & & 17.30 & 0.12 & 23.05 & 0.51 & - & - & - & - \\
\hline
\end{tabular}

$A N D^{\mathrm{a}}$, anidulafungin $\left(0.5 \mu \mathrm{g} \mathrm{mL}^{-1}\right) ; A N D^{\mathrm{b}}$, anidulafungin $\left(1 \mu \mathrm{g} \mathrm{mL}^{-1}\right) ; A M B$, amphotericin $\mathrm{B}\left(2.5 \mu \mathrm{g} \mathrm{mL} L^{-1}\right) ; A N D / A M B$, association of anidulafungin and amphotericin $\mathrm{B}\left(0.5 / 2.5 \mu \mathrm{g} \mathrm{mL}^{-1}\right)$

CA, C. albicans; $C P$, C. parapsilosis; $C T$, C. tropicalis

$C F U$, colony-forming units

of America [12,36]. ALT was used because it is an already well-described technique, that has been gaining prominence, and is extensively studied. It consists of the diffusion of a high concentration (up to 1000 times the MIC) of the antifungal solution alone or in combination with other components in the lumen of the catheter, leaving it to act for a period that can vary from hours to days $[8,36,40]$. In ALT, the interaction of the antifungal agent with the material can alter the surface and inhibit or hinder cell adhesion or the agent can be released from the surface and exhibit inhibitory activity on planktonic cells $[13,22]$. The AND showed the best results, with $100 \%$ inhibition of biofilm formation on the catheter, followed by AMB but with a high coefficient of variation in its results. Both, AMB at high concentrations such as echinocandins, despite strongly inhibiting biofilms in biomaterials, complete action $(100 \%)$ on biofilm is not commonly reported $[8,36$, 44]. Likewise, different authors concluded, through in vitro and in vivo data analysis, that echinocandins (preferably micafungin or AND) and AMB (liposomal AMB or AMB deoxycholate) proved to be very promising strategies for use in ALT treatment $[36,44,47]$. However, regarding the activity of amphotericin $\mathrm{B}$, there is no consensus, although numerous studies have shown good activity of AMB [33, 48]. Due to its variability, the success rate of this technique changes according to the drugs used; in vivo data are limited to case reports $[8,49]$.

The combination of AND and AMB was also tested on polyurethane central venous catheter. AND and AMB alone demonstrated a significant reduction in activity, in parallel with the reduction in concentration (AND $1 \mu \mathrm{g} \mathrm{mL}^{-1}$ and $0.5 \mu \mathrm{g} \mathrm{mL}^{-1}$; AMB $8 \mu \mathrm{g} \mathrm{mL}^{-1}$ and $2.5 \mu \mathrm{g} \mathrm{mL}^{-1}$ ). Similarly, Basas et al. demonstrated on silicon disks that AND at a concentration of $1 \mu \mathrm{g} \mathrm{mL}^{-1}$ was able to eradicate at least $90 \%$ of the biofilm; however, when at lower concentrations $(0.125$ $0.25 \mu \mathrm{g} \mathrm{mL}^{-1}$ ), efficacy was reduced to about $50 \%$ of eradication [50]. Then, the association of AND and AMB in the lower concentrations was evaluated and a significant increase in activity was observed: above $90 \%$ of activity on biofilms. The synergistic action is most likely due to the different targets on which these antifungal agents act. AND has its mechanism of action on one of the major enzymes involved in fungal cell wall biosynthesis, 1,3- $\beta$-D-glucan synthase, in order to compromise the synthesis of 1,3- $\beta$-D-glucan, an important polysaccharide structural component of the fungal cell wall [34, 51]. The action of AND culminates in the loss of cell wall integrity and facilitates the entry and action of AMB on the fungal cell, since this has direct interaction with ergosterol, an essential component of the fungal cell membrane $[11,34,48$, 52]. AND causes severe stress on the cell wall, leading to lysis of fungal cells. Also, there is the action of AMB, which results in pore formation, membrane permeabilization, and leakage of cytoplasmic content, leading to fungal cell death, even both at low concentrations [34, 51, 52].

Among the tested agents, AND has also shown best results with less variability on mature biofilm eradication $(\sim 100 \%$ activity for practically all strains). Despite the success in biofilm eradication demonstrated by most of the tested antifungal agents, the challenge of mature biofilms in the clinic is still 

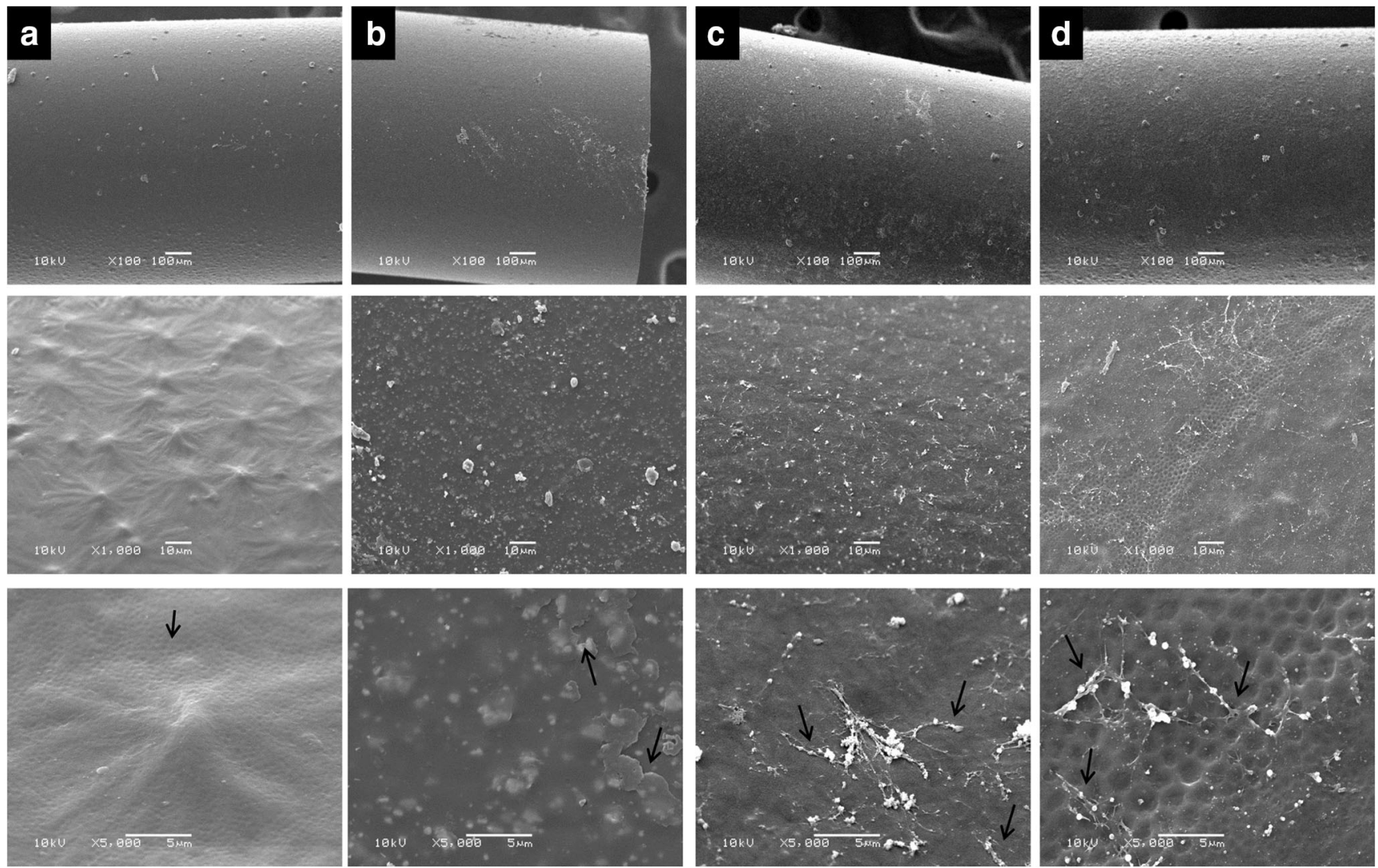

Fig. 2 Scanning electron microscopy of polyurethane catheter samples. a Uncoated device surface (arrow indicates subtle porosity of the catheter surface). b Surface coating by the formulation film without the addition of antifungal agent (arrows indicate the covering of the catheter surface in the form of layers). c Device surface covered by formulation film containing anidulafungin (AND) $1 \mu \mathrm{g} \mathrm{mL}^{-1}$ (the arrows indicate the

largely unknown. Biofilm formation by Candida spp. varies depending on the type of material in which it grows [53]. Both ALT and the treatment of biofilms already formed on biomaterials with antifungal agents have proved to be possible strategies to combat biofilm. Although, as a whole, the already formed biofilm is more difficult to handle. In addition, the tested compounds had access to the biofilm formed in the catheter as a whole. It is known that the intraluminal formation and the difficulty of these drugs in accessing the biofilms in vivo represent important factors related to therapeutic failure [36]. This fact shows the need to develop a new strategy to combat this type of fungal growth.

The ALT treatment strategies, despite being successful, use large doses of these agents, and their activity is restricted to the biofilm formed in the catheter lumen. Moreover, biofilm infections involving the tip of the catheter or the external surface and adjacent tissues may contribute to an increase in the failure rate $[33,44,49]$. Thus, strategies for coating catheters to prevent the initial fixation of fungal (microbial) cells on their surface in order to prevent biofilm from becoming established are important [15].
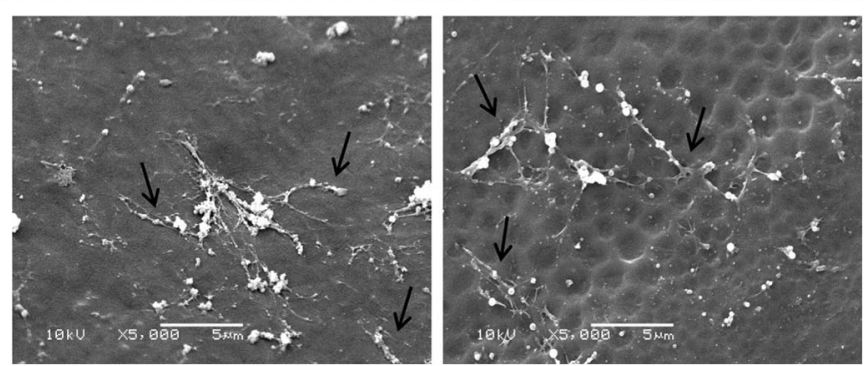

covering of the catheter surface in the form of very irregular networks, the pores on the surface of the device are not observed). $\mathbf{d}$ Catheter covered by anidulafungin/amphotericin B (AND/AMB 0.5/ $2.5 \mu \mathrm{g} \mathrm{mL}^{-1}$ ) formulation (arrows indicate the coverage of the catheter surface in the form of a very irregular mesh, the pores on the surface of the device can be observed)

In this context, the development of a film-forming system incorporated with the most active studied compounds, is justified.

Hydrogels and gels containing AMB have already been presented as formulations with high local in vitro antifungal capacity and in the treatment of vascular catheters involving biofilms of Candida spp. with good activity, however, at higher concentrations than those used in this study $[15,49]$. The performance of the AMB-containing film-forming system tested in this work is largely due to its low dose in the formulation since it was previously shown that the $\mathrm{AMB}$ activity in biofilms requires high drug concentrations.

The promising attribute of these antifungal formulations was demonstrated by their ability to inhibit biofilm formation. The formulations containing the combination of drugs and the one containing $1 \mu \mathrm{g} \mathrm{mL}^{-1}$ of AND presented the best results. These formulations had low variability and inhibition above $90 \%$ (90.50-98.26\% and $93.41-98.26 \%$, respectively). The combination has the advantages of reducing the development of resistance and the required concentrations of antifungal agents [54]. 
In a similar idea, Zhou et al. tested three formulations of antibacterial hydrogel, which were used in the catheter coating and showed up to $99.6 \%$ activity for the bacterial biofilm [55]. Chitosan hydrogels follow the same principle in medical devices and are very effective in controlling the formation of biofilms of numerous Candida species including in vivo rat model assays [36, 40]. However, all formulations previously tested by other authors have composition that differs from the formulation presented in this study. The formulation tested in this study polymerizes to form a film in situ and it has an easy fabrication method, proving to be promising [17, 31]. In addition, the formulation showed no changes in drying time or stickiness with the addition of different antifungal agents, demonstrating that, in practical criteria, there is no significant influence by these antifungal agents.

The use of hydrophilic polymers, such as Carbopol, allows diffusion of the compound to the film surface [56]. The micrographs obtained show that the device without coating by the film forming system presents surface with subtle porosity, which are structures that can facilitate the installation of the microorganism for later formation of the biofilm. The film formed by the formulation without the addition of antifungal agents showed the ability to cover the pores of the device by forming layers on its surface. The addition of antifungal agents modifies the morphology of this coating film, which can be observed in the form of networks that interconnect and extend across the catheter surface. Although in the film containing the combination (AND/AMB), the mesh formed did not clog the pores on the device surface; the film efficiently deposited on it as observed by the activity profile. Thus, the formulation, besides covering the catheter surface and modifying the interaction of the fungus with the device while inhibiting the adhesion of fungal cells, can, still, gradually release the antifungal agent, prolonging the time of action $[13,56]$. Although there is a micromorphological change in the coating film, the macromorphology remains visually unchanged (film with and without antifungal agents) and physical properties are also maintained. Thus, a new biofilmfighting strategy based on an antimicrobial system is proposed. This formulation has a high promising value as it can provide prolonged contact time of the drug against fungal cells, providing increased biofilm prevention efficacy [18]. The formulation is able to maintain the activity of the incorporated antifungal agents [27] and in case of this study, was able to maintain the excellent performance of the antifungal agents in inhibiting biofilm formation.

\section{Conclusion}

Considering the results obtained, we can conclude that there is an indirect influence of the species involved with the susceptibility in relation to the different treatment approaches, as well as the properties of the surface on which the biofilm is formed, and thus, on susceptibility to antifungal agents. The AND demonstrated superiority over the other antifungal agents; AMB also showed considerable activity, however, in high concentrations, which is related to toxicity, mainly nephrological. Due to the synergistic activity presented, the AND/AMB combination allows to reduce the concentrations of both, favoring the profile of lower toxicity and cost and reducing the development of resistance, proving to be the best option in the therapy of biofilm-related infections. The formulation of the combination showed great potential for use in biofilm prevention, with potential for inhibition greater than $90 \%$. In addition to this novel formulation maintaining the activity of the antifungal agent in relation thereto in solution, the film forming system has the ability to prolong the contact time of the surface with the antifungal agent due to the formation of the film, thereby also the time of counted with the fungal cells, preventing their adherence. Thus, it may represent a promising alternative for future studies of its potential for clinical use in the prevention of Candida spp. biofilm.

Acknowledgments The authors thank the Núcleo de Apoio Estatístico and Centro de Microscopia e Microanálise, Campus do Vale, Universidade Federal do Rio Grande do Sul, Porto Alegre/RS, Prof. Dr. Patrícia Valente da Silva, and to Dr. Bruna Pippi. A. M. Fuentefria is grateful to $\mathrm{CNPq}$ for their research fellowships.

Funding information This work was supported by the Brazilian agencies Coordenação de Aperfeiçoamento de Pessoal de Nível Superior (CAPES), Conselho Nacional de Desenvolvimento Científico e Tecnológico (CNPq), and Fundação de Amparo a Pesquisa do Estado do Rio Grande do Sul (FAPERGS-EDITAL 04/2016 -PRONUPEQ 2016).

\section{Compliance with ethical standards}

Conflict of interest The authors declare that they have no conflicts of interest.

\section{References}

1. Chang YL, Yua SJ, Heitmanb J, Wellingtonc M, Chen YL (2017) New facets of antifungal therapy. Virulence 8:222-236. https://doi. org/10.1080/21505594.2016.1257457

2. Pappas PG, Lionakis MS, Arendrup MC, Zeichner LO, Kullberg BJ (2018) Invasive candidiasis. Nat Rev Dis Primers 4(Article number: 18026). https://doi.org/10.1038/nrdp.2018.26

3. Guinea J (2014) Global trends in the distribution of Candida species causing candidemia. Clin Microbiol Infect 20:5-10. https://doi. org/10.1111/1469-0691.12539

4. Ramage G, Saville SP, Thomas DP, López-Ribot J (2005) Candida biofilms: an update. Eukaryot Cell 4:633-638. https://doi.org/10. 1128/EC.4.4.633-638.2005

5. Ramage G, Rajendran R, Sherry L, Williams C (2012) Fungal biofilm resistance. Int J Microbiol:1-14. https://doi.org/10.1155/2012/ 528521 
6. Silva S, Rodrigues CF, Araújo D, Rodrigues ME, Henriques M (2017) Candida species biofilms' antifungal resistance. J Fungi 3: 8. https://doi.org/10.3390/jof3010008

7. Tobudic S, Kratzer C, Lassnigg A, Graninger W, Presterl E (2010) In vitro activity of antifungal combinations against Candida albicans biofilms. J Infect Chemother 65:271-274. https://doi.org/ 10.1093/jac/dkp429

8. Bouza E, Guinea J, Guembe M (2015) The role of antifungals against Candida biofilm in catheter-related Candidemia. Antibiotics 4:1-17. https://doi.org/10.3390/antibiotics4010001

9. Tascini C, Sozio E, Corte L, Sbrana F, Scarparo C, Ripoli A, Bertolino G, Merelli M, Tagliaferri E, Corcione A, Bassetti M, Cardinali G, Menichetti F (2017) The role of biofilm forming on mortality in patients with candidemia: a study derived from real world data. Infect Dis Ther 0:1-6. https://doi.org/10.1080/ 23744235.2017.1384956

10. Mermel LA, Allon M, Bouza E, Craven DE, Flynn P, O'Grady NP, Raad II, Rijnders BJA, Sherertz RJ, Warren DK (2009) Clinical practice guidelines for the diagnosis and management of intravascular catheter-related infection: update by the infectious diseases. https://doi.org/10.1086/599376

11. De Cremer K, Staes I, Delattin N, Cammue BP, Thevissen K, De Brucker K (2015) Combinatorial drug approaches to tackle Candida albicans biofilms. Expert Rev Anti-Infect Ther 13:973984. https://doi.org/10.1586/14787210.2015.1056162

12. Ramage G, Robertson SN, Williams C (2014) Strength in numbers: antifungal strategies against fungal biofilms. Int $\mathrm{J}$ Antimicrob Agents 43:114-120. https://doi.org/10.1016/j.ijantimicag.2013.10. 023

13. Karkhanis YD, Schmatz DM (1998) Novel enzyme-linked immunoassay to determine nanogram levels of Pneumocandins in human plasma. J Clin Microbiol 36:1414-1418

14. Arciola CR, Campoccia D, Speziale P, Montanaro L, Costerton JW (2012) Biofilm formation in Staphylococcus implant infections. A review of molecular mechanisms and implications for biofilmresistant materials. Biomaterials 33:5967-5982. https://doi.org/10. 1016/j.biomaterials.2012.05.031

15. Giles C, Lamont-Friedrich SJ, Michl TD, Griesser HJ, Coad BR (2018) The importance of fungal pathogens and antifungal coatings in medical device infections. Biotechnol Adv 36:264-280. https:// doi.org/10.1016/j.biotechadv.2017.11.010

16. Iñigo M, Pemán J, Del Pozo JL (2012) Antifungal activity against Candida biofilms. Int J Artif Organs 35:780-791

17. Been RA, Bernatchez SF, Conrad-Vlasak DM, Asmus RA, Ekholm BP, Parks PJ (2016) In vivo methods to evaluate a new skin protectant for loss of skin integrity. Wound Repair Regen 24:851-859. https://doi.org/10.1111/wrr.12455

18. Yang S, Yang Y, Cui S, Feng Z, Du Y, Song Z, Tong Y, Yang L, Wang Z, Zeng H, Zou Q, Sun H (2018) Chitosan-polyvinyl alcohol nanoscale liquid film-forming system facilitates MRSA-infected wound healing by enhancing antibacterial and antibiofilm properties. Int J Nanomedicine 13:4987-5002. https://doi.org/10.2147/ijn. s161680

19. Johnson MD, MacDougall C, Ostrosky-Zeichner L, Perfect JR, Rex JH (2004) Combination antifungal therapy. Antimicrob Agents Chemother 48:693-715. https://doi.org/10.1128/AAC.48.3.693715.2004

20. Gulati M, Nobile CJ (2016) Candida albicans biofilms: development, regulation, and molecular mechanisms. Microbes Infect 18: 310-321. https://doi.org/10.1016/j.micinf.2016.01.002

21. Rex JH, Clinical and Laboratory Standards Institute (2008) Reference method for broth dilution antifungal susceptibility testing of yeasts: approved standard, 3rd edn. National Committee for Clinical Laboratory Standards, Wayne

22. Bachmann SP, Walle KV, Ramage G, Patterson TF, Wickes BL, Graybill JR, López-Ribot JL (2002) In vitro activity of caspofungin against Candida albicans biofilms. Antimicrob Agents Chemother 46:3591-3596. https://doi.org/10.1128/AAC.46.11.3591-3596. 2002

23. Pippi B, Machado GRM, Bergamo VZ, Alves RJ, Andrade SF, Fuentefria AM (2018) Clioquinol is a promising preventive morphological switching compound in the treatment of Candida infections linked to the use of intrauterine devices. J Med Microbiol 67: 1655-1663. https://doi.org/10.1099/jmm.0.00085

24. Stepanović S, Vuković D, Hola V, Di Bonaventura G, Djukić S, Ćirković I, Ruzicka F (2007) Quantification of biofilm in microtiter plates: overview of testing conditions and practical recommendations for assessment of biofilm production by staphylococci. APMIS 115:891-899. https://doi.org/10.1111/j.1600-0463.2007. apm 630.x

25. Ramage G, Walle KV, Wickes BL, López-Ribot JL (2001) Standardized method for in vitro antifungal susceptibility testing of Candida albicans biofilms. Antimicrob Agents Chemother 45: 2475-2479. https://doi.org/10.1128/AAC.45.9.2475-2479.2001

26. Shuford JA, Piper KE, Steckelberg JM, Patel R (2007) In vitro biofilm characterization and activity of antifungal agents alone and in combination against sessile and planktonic clinical Candida albicans isolates. Diagn Microbiol Infect Dis 57:277281. https://doi.org/10.1016/j.diagmicrobio.2006.09.004

27. Machado GRM, de Andrade SF, Pippi B, Bergamo VZ, Berlitz SJ, Lopes W, Lavorato SN, Guerreiro ICK, Vainstein MH, Teixeira ML, Alves RJ, Fuentefria AM (2019) Chloroacetamide derivatives as a promising topical treatment for fungal skin infections. Mycologia 111:612-623. https://doi.org/10.1080/00275514.2019. 1620550

28. Cheng KC, Demirci A, Catchmark JM (2011) Pullulan: biosynthesis, production, and applications. Appl Microbiol Biotechnol 92: 29-44. https://doi.org/10.1007/s00253-011-3477-y

29. Schroeder IZ, Franke P, Schaefer UF, Leh C-M (2007) Development and characterization of film forming polymeric solutions for skin drug delivery. Eur J Pharm Biopharm 65:111-121. https://doi.org/10.1016/j.ejpb.2006.07.015

30. Paradkar M, Thakkar V, Soni T, Gandhi T, Gohel M (2015) Formulation and evaluation of clotrimazole transdermal spray. Drug Dev Ind Pharm 41:1718-1725. https://doi.org/10.3109/ 03639045.2014.1002408

31. Kathe K, Kathpalia H (2017) Film forming systems for topical and transdermal drug delivery. Asian J Pharm Sci 12:487-497. https:// doi.org/10.1016/j.ajps.2017.07.004

32. Tran TTD, Tran PHL (2019) Controlled release film forming systems in drug delivery: the potential for efficient drug delivery. Pharmaceutics 11:290. https://doi.org/10.3390/ pharmaceutics 11060290

33. Girardot M, Imbert I (2016) Novel strategies against Candida biofilms: interest of synthetic compounds. Future Microbiol 11: 69-79. https://doi.org/10.2217/fmb.15.118

34. Robbins N, Wright GD, Cowen LE (2016) Antifungal drugs: the current armamentarium and development of new agents. Microbiol Spectrum 4:903-922. https://doi.org/10.1128/microbiolspec.funk0002-2016

35. Fuentefria AM, Pippi B, Dalla Lana DF, Donato KK, de Andrade SF (2017) Antifungals discovery: an insight into new strategies to combat antifungal resistance. Lett Appl Microbiol 66:2-13. https:// doi.org/10.1111/lam.12820

36. Bujdáková H (2016) Management of Candida biofilms - state of knowledge and new options for prevention and eradication. Future Microbiol 11:235-251. https://doi.org/10.2217/fmb.15.139

37. Hacioglu M, Tan ASB, Dosler S, Inan N, Otuk G (2018) In vitro activities of antifungals alone and in combination with tigecycline against Candida albicans biofilms. PeerJ 6:e5263. https://doi.org/ $10.7717 /$ peerj. 5263 
38. Turan H, Demirbilek M (2018) Biofilm-forming capacity of bloodborne Candida albicans strains and effects of antifungal agents. Rev Argent Microbiol 50:62-69. https://doi.org/10.1016/j.ram. 2017.05.003

39. Chandra J, Mukherjee PK (2015) Candida biofilms: development, architecture and resistance. Microbiol Spectrum 3. https://doi.org/ 10.1128/microbiolspec.MB-0020-2015

40. Cavalheiro M, Teixeira MC (2018) Candida biofilms: threats, challenges and promising strategies. Front Med 5(ARTICLE 328). https://doi.org/10.3389/fmed.2018.00028

41. Silva S, Henriques M, Martins A, Oliveira R, Williams D, Azeredo J (2009) Biofilms of non-Candida albicans, Candida species: quantification, structure and matrix composition. Med Mycol 47:681689. https://doi.org/10.3109/13693780802549594

42. Pannanusorn S, Fernandez V, Romling U (2013) Prevalence of biofilm formation in clinical isolates of Candida species causing bloodstream infection. Mycoses 56:264-272. https://doi.org/10. 1111/myc. 12014

43. Núñez-Beltrán A, López-Romero E, Cuéllar-Cruz M (2017) Identification of proteins involved in the adhesion of Candida species to different medical devices. Microb Pathog 107:293-303. https://doi.org/10.1016/j.micpath.2017.04.009

44. Fujimoto K, Takemoto K (2018) Efficacy of liposomal amphotericin B against four species of Candida biofilms in an experimental mouse model of intravascular catheter infection. $\mathrm{J}$ Infect Chemother:1-7. https://doi.org/10.1016/j.jiac.2018.08.011

45. Hamill RJ (2013) Amphotericin B formulations: a comparative review of efficacy and toxicity. Drugs 73:919-934. https://doi.org/10. 1007/s40265-013-0069-4

46. Valentín A, Cantón E, Pemán J, Fernandez-Rivero ME, Tormo-Mas MA, Martínez JP (2016) In vitro activity of anidulafungin in combination with amphotericin B or voriconazole against biofilms of five Candida species. J Antimicrob Chemother 71:3449-3452. https://doi.org/10.1093/jac/dkw316

47. Walraven CJ, Lee SA (2012) Antifungal lock therapy. Antimicrob Agents Chemother 57:1-8. https://doi.org/10.1128/AAC.01351-12

48. Silva S, Negri M, Henriques M, Oliveira R, Williams DW, Azeredo J (2012) Candida glabrata, Candida parapsilosis and Candida tropicalis: biology, epidemiology, pathogenicity and antifungal resistance. FEMS Microbiol Rev 36:288-305. https://doi.org/10. 1111/j.1574-6976.2011.00278.x

49. Nett JE (2014) Future directions for anti-biofilm therapeutics targeting Candida. Expert Rev Anti-Infect Ther 12:375-382. https://doi.org/10.1586/14787210.2014.885838

50. Basas J, Morer A, Ratia C, Martín MT, Del Pozo JL, Gomis X, Rojo-Molinero E, Torrents E, Almirante B, Gavalda J (2016) Efficacy of anidulafungin in the treatment of experimental Candida parapsilosis catheter infection using an antifungal-lock technique. J Antimicrob Chemother 71:2895-2901. https://doi. org/10.1093/jac/dkw251

51. Campoy S, Adrio JL (2017) Antifungals. Biochem Pharmacol 133: 86-96. https://doi.org/10.1016/j.bcp.2016.11.019

52. Kathiravan MK, Salake AB, Chothe AS, Dudhe PB, Watode RP, Mukta MS, Gadhwe S (2012) The biology and chemistry of antifungal agents: a review. Bioorg Med Chem 20:5678-5698. https:// doi.org/10.1016/j.bmc.2012.04.045

53. Estivill D, Arias A, Torres-Lana A, Carrillo-Muñoz AJ, Arévalo MP (2011) Biofilm formation by five species of Candida on three clinical materials. J Microbiol Methods 86:238-242. https://doi. org/10.1016/j.mimet.2011.05.019

54. Cui J, Ren B, Tong Y, Dai H, Zhang L (2015) Synergistic combinations of antifungals and antivirulence agents to fight against Candida albicans. Virulence 6:362-371. https://doi.org/10.1080/ 21505594.2015.1039885

55. Zhou C, Song H, Loh J, She J, Deng L, Bo L (2018) Grafting antibiofilm polymer hydrogel film onto catheter by SARA SIATRP. J Biomater Sci Polym Ed:1-27. https://doi.org/10.1080/ 09205063.2018 .150726

56. Ammar HO, Ghorab M, Mahmoud AA, Makram TS, Ghoneim AM (2011) Rapid pain relief using transdermal film forming polymeric solution of ketorolac. Pharm Dev Technol 18:1005-1016. https://doi.org/10.3109/10837450.2011.627867

Publisher's note Springer Nature remains neutral with regard to jurisdictional claims in published maps and institutional affiliations. 